\title{
GRADUATE INTERNS' EXPERIENCES: A CAREER SUCCESS ORIENTATIONS APPROACH
}

\author{
B KANYE \\ F CROUS \\ (fcrous@uj.ac.za) \\ Programme in Industrial Psychology \\ Department of Human Resource Management \\ University of Johannesburg
}

\begin{abstract}
Organisations are challenged to achieve optimal business results by specifically attracting and retaining talented human resources, while simultaneously creating environments where individuals feel their own personal career aspirations are fulfilled. This study examined graduate interns' experiences using career success orientations as a framework. Data were collected using a card sorting technique and semi-structured interviews. The data were then analysed and used as a guide for internship programme design. Implications of the findings are discussed.
\end{abstract}

Key words: Graduate internship programmes, differentiated career success orientations, ethnographic analysis, card sorting technique, interviews

Organisations are constantly challenged to attract individuals who will add value to the business and contribute to organisational success. Finding talented people who will fit in with the organisations culture, vision and strategic goals is not always easy. This challenge is particularly real in South Africa where there is acute shortage of skilled people (Boninelli, 2004). In an effort to attract and retain high calibre graduate interns, some organisations invest in internship programmes.

For most graduates, an internship programme is their first formal introduction to the world of work, and as such, may impact significantly on shaping their careers in both the organisational entry and establishment phases of their career cycle (Greenhaus, Callanan \& Godshalk, 2000). In line with Schein's (1978) thinking, an internship programme may facilitate this in the following ways: dealing with the reality shock of the world of work and organisational membership, becoming an effective member of the organisation as quickly as possible and adjusting to the daily work demands. Internship programmes serve an educational function as they expose interns to real life problems and information that is simply not available in a classroom setting (Gabris \& Mitchel, 1989).

Dodge and McKeough (2003) explained an internship as an undertaking with a focus on the provision of "real world" experience to those whose preoccupation has been with formal learning, or who are not familiar with a particular body of work. They also explain that for the employer, interns represent an opportunity to bring in bright and energetic people. These interns are desirable as they inject new talent into the organisation. Buhlungu and Metcalfe (2001) indicated that internship programmes should be rigorously conceptualised, planned and provide for statements of expected outcomes and mechanisms for evaluation. This should to some extent lead to a commitment by the organisation and the interns to the programme.

Internship programmes typically include rotating interns between various functions of the business or they are placed in a specific job role for a defined period, typically a year (Dodge \& McKeough, 2003). Both these methods focus on exposing the interns to a job role or a series of job roles that are important to the organisation while providing practical learning opportunities for the interns. Rotating interns provide them with a holistic perspective of how the organisation functions, and encourages them to build relationships with people from different functions, levels and backgrounds. Interns are expected to integrate into work environments that are at times pressurised, tense and stressful. Carlin (2002) is of the view that creating a well-designed internship programme should be part of the ethical agenda in any graduate programme.
Internship programmes are useful in integrating graduate talents and career interests with organisational priorities (Carlin, 2002). The design of internship programmes should allow interns to learn by doing and help them to focus on their own career goals and objectives (Jones, 2006). These programmes are generally designed around a job, project, or set of deliverables. Given then the design of a typical internship programme, it seems that the design focuses predominantly on what Derr and Laurent (1989) referred to as the external career, which emphasises what the organisation values and rewards in its employees. It is institutional by nature (Bailyn, 1989) and it reflects the realities, constraints, opportunities and actual job sequences in the world of work (Schein, 1990) as well as the salient features and demands of their social context (Wellin \& Fine, 2001). As such, the career self-concept, or internal career of the interns, is not emphasised by the way internship programmes are designed. The internal career is a self-definition of a career; a person's own subjective idea of work life, and that person's role in it - It reflects a person's internal psychological values or needs (Derr \& Laurent, 1989). The external career is limited to the organisation's singular view of career success, whereas the internal career success implies diversity (Derr, 1986). In order to explore the diversity of internal career success, the work of at least three theorists should be considered, namely that of Schein $(1978,1990,1996)$, Driver (1982) and Derr (1986).

Schein's work $(1978,1990,1996)$ on career orientations, which he termed "career anchors", introduced the operationalisation of the multi-dimensionality of the internal career construct and its relationship to career success. He described the career anchor as a pattern of self-perceived talents, motives, and values that serve to guide, constrain, stabilise and integrate a person's career. $\mathrm{He}$ furthermore indicated that the career anchor functions in a person's work life as a way of organisational experience, identifying areas of contribution and generating criteria for work settings that people like to function in and developing criteria for success, by which people will measure themselves. His work is based on the foundation that regardless of the present job people hold, their future decisions about work will be easier and valid if people have a clear understanding of their own orientation towards work, their motives, their values and their perceived talents. A career anchor operates as a genuine enabler on career decisions.

Schein (1978) furthermore indicated that a standard by which an individual measures his or her own success largely reflects that person's internal career orientation, or anchor. Based on a longitudinal study, he introduced five career orientations/career 
anchors, namely; technical/functional competence, general managerial competence, autonomy/independence, security or stability, and entrepreneurial creativity. Schein (1990) later added three more to his original list, namely; service/dedication to a cause, pure challenge and lifestyle.

Driver (1982), in line with Schein's work constructed the idea of career self-concept. He indicated that an individual's definition of career success grows out of a habit of thought, motives and decision-making styles thus becoming the foundation that guides the individual's long-term career choices. Results from his study indicated that some individuals defined career success as "spiral" in the form of continued growth and self-renewing experiences; some "steady-state" individuals wanted long-term stability and relatively unchanging work identity, others were "transitory" in that they saw a successful career having a variety of different experiences, and the "linear" people viewed success as upward mobility to the top of the organisation or profession. The career self-concept provides for self-assessment activities for the enhancement of self-insight and informed choice when faced with career adjustment or adaptation (Coetzee \& Schreuder, 2002).

Derr (1986, p.5) modified the construct of career orientations and indicated that career success is "being able to both live out the subjective and personal values one really believes in and to make contributions to the world of work", He suggested the following formula underlying his concept: motives + values + talents - perceived constraints $=$ career success orientation .

He expressed the diversity of individualised career success in terms of five distinct career success orientations; namely:

Getting Ahead (making it to the top of the hierarchy and status symbols).

The Getting Ahead career orientation is characterised by a desire for upward mobility. In order to obtain more influence, status, and financial remuneration, the individual seeks promotion within a hierarchy of positions, or advancement within the status system. Individuals pursuing such a strategy are most often found in large organisations or professional associations.

Getting Secure (achieving recognition, job security, respect, and getting insider status).

The Getting Secure career orientation is characterised by individuals who regard career success as the achievement of long-term job security, good benefits, and a sense of identity, order and place. These persons exchange dedication, loyalty, and service for financial benefits, job security and reciprocal appreciation and respect. Getting Secure individuals seek out organisations with a reputation for treating employees benevolently and fairly and companies that offer lifelong employment.

Getting Free (obtaining maximum control over work processes). The Getting Free career orientation is characterised by individuals who don't seek upward mobility; instead they seek freedom. They like marginal positions where they can have space, personal autonomy, loose supervision, and the responsibility for outcomes. They don't like being bound by the processes, norms, and rules of others. Such individuals might become experts in a valued speciality, and then negotiate their freedom - knowledge is power and expertise is freedom.

Getting High (obtaining excitement, challenge, adventure and "cutting edge" opportunities).

The Getting High career orientation is characterised by individuals seeking to move, often laterally, to the centre of the action, as well as seeking adventure and creativity. They thrive on exciting work and also need autonomy, although they would not trade freedom for exciting work. The Getting High person can exist in large or small organisations, depending on the opportunities, but will usually view bureaucratic rules as constraints.
Getting Balanced (achieving a meaningful balance among work, relationships and self-development, so that work does not become either too engrossing or too uninteresting).

The Getting Balanced career orientation is characterised by individuals who, during certain periods of their careers and lives, may stress one dimension at the expense of others, but at the earliest opportunity they will try to restore the equilibrium. Work is very important to them, but it is not allowed to devour the other areas of their life. Likewise, they do not allow their private lives to keep them from investigating and challenging their work lives.

There are clear similarities between the three theories mentioned above. What Derr referred to as getting ahead is reflected in Driver's work as "linear" and Schein referred to as "general managerial competence", all carrying a central theme of upward mobility. What Derr referred to as getting secure, Driver defined as "steady-state" while Schein talked about "security-oriented", all with a theme of security and predictability. What Derr termed getting free is reflected in Driver's work as "transitory", while Schein referred to "autonomy/independence" all emphasising learning, variety of different experiences and carving out one's own space within the organisation. What Derr referred to as Getting high was reflected in Driver's work as "spiral" and in Schein's work as "pure challenge" indicating the need for adventure and excitement in work. What Derr termed getting balanced is defined in Schein's work as "life-style" that advocated the need for balance between professional and private lives. Driver did not reflect this orientation in his work.

The theories developed by Schein, Driver and Derr have been validated by empirical research. For example: Van Vuuren \& Fourie (2000) for career anchors; Coetzee \& Schreuder (2002) for career concepts; Carlson \& Derr (2003); Chompookum \& Derr (2004); and Rosslee, Crous \& Schepers (1999) for career success orientations.

For the purpose of this study, Derr's theory was selected since it focuses specifically on the idea of career success more so than those of Schein's or Driver's. Derr's (1986) theory implies that the success of an internship programme should not only take into consideration objective organisational criteria for success, but should especially consider the diversity of individuals' subjective criteria for career success.

The primary aim of this study, therefore, was to ascertain certain graduate interns' experiences of an internship programme in relation to their individual career success orientations and to what extent this may provide for the development of an internship programme that is multi faceted in terms of career success and is intern centred.

\section{RESEARCH DESIGN}

\section{Research Approach}

In order to collect rich, detailed and contextual data on career success orientations from interns, qualitative research (Denzin \& Lincoln, 2000) was regarded as the appropriate approach. This approach afforded interns an opportunity to provide relevant information on their career experiences since joining the organisation and to reflect on the development of their respective career success orientations. An ethnographic research strategy (Spradley, 1979) was executed by means of a card sorting technique and semi-structured interviews. Therefore, in line with Terre Blanche and Kelly's (1999) thinking it is assumed 'that peoples' subjective experiences are real and should be taken seriously (ontology), that we can understand others' experiences by interacting with them and listening to what they tell us (epistemology), and that qualitative research techniques are best suited to this task (methodology)". 


\section{Research methodology \\ Participants}

All participants were drawn from a single financial institution. Although participation in this research was voluntary, care was taken to ensure that the final group represented all the intake years from 2000 to 2005. The organisation had a total of 30 interns remaining from the class of 2000 to 2005. A total number of 18 interns were interviewed, a $60 \%$ representation of the total graduate population still with the organisation. The following biographical data were recorded; gender, race, age group, period with organisation and year, and academic qualifications. (See Table 1).

\section{TABLE 1}

DEMOGRAPHIC CHARACTERISTICS OF THE INTERNS

\begin{tabular}{|c|c|}
\hline Gender & Male $=13(72 \%) ;$ Female $=5(28 \%)$ \\
\hline Race & White $=11(61 \%) ;$ Black African $=7(39 \%)$ \\
\hline Age group (18-28) & 16 \\
\hline Age group (29-43) & 2 \\
\hline $\begin{array}{l}\text { Period with } \\
\text { organisation }\end{array}$ & $\begin{array}{l}1 \text { year }=7 ; \\
2 \text { years }=2 ; \\
3 \text { years }=1 ; \\
4 \text { years }=3 ; \\
5 \text { years }=4 ; \\
6 \text { years }=1\end{array}$ \\
\hline $\begin{array}{l}\text { Academic } \\
\text { qualification }\end{array}$ & $\begin{array}{l}\text { All interns had completed at least a 3-year bachelor's } \\
\text { business degree. } \\
\text { BSc Actuarial Science (3) } \\
\text { BSc Statistics (1) } \\
\text { BSc Computer Science \& Mathematics (1) } \\
\text { BSc Physiology \& Archaeology (1) } \\
\text { BCom Hons Economics, Accounting \& Investments (1) } \\
\text { BCom Hons Business Management (2) } \\
\text { BCom Hons Marketing \& Strategy (1) } \\
\text { BCom Information Systems, Accounting (2) } \\
\text { BCom Insurance \& Economics (1) } \\
\text { BCom Economics \& Finance (1) } \\
\text { BCom Informatics (1) } \\
\text { BCom Accounting (1) } \\
\text { BCom Marketing (1) } \\
\text { BSoc Science Philosophy, Economics \& Political } \\
\text { Science (1) }\end{array}$ \\
\hline
\end{tabular}

Data Gathering and Analysis

A local study on career success orientations by Rosslee, Crous and Schepers (1999) identified a different factor structure namely; freedom seekers (a combination of getting free, getting ahead, and getting high), comfort seekers (a combination of getting secure and getting balanced), equilibrium seekers (a combination of getting high, getting ahead, getting free, getting balanced and getting secure) and competition seekers (a combination of getting high and getting ahead). However, for the purpose of this study, Derr's original structure of career success was utilised.

\section{Card sorting technique}

Spradley (1979) indicated that most of the time any internal structure, as it is known to participants, remains tacit, i.e. outside their awareness. The researcher has to devise ways to discover this tacit knowledge. In this study, five cards each with a description of the essence of a particular career success orientation, i.e. getting high, getting balanced, getting free, getting ahead and getting secure were used to bring the concept of career success to the interns' awareness and to help them to explore that construct in detail.

Writing descriptions on cards helped to elicit, verify and discuss a domain; in this case, career success orientation in the context of an internship programme (Spradley, 1979). Card sorting is a type of semi-structured interview that provides a non-evasive way of assisting participants to organise knowledge and unpack concepts in order to understand them and their meaning better (Spradley, 1979; de Gouveia, Van Vuuren \& Crafford, 2005). For the purposes of this study, the card-sorting technique served as a way of introducing Derr's (1986) concept of career success orientations and as a map for interns to discover and make sense of their own internal career success orientations. Derr's career success orientation was used as it provided a clear and simple framework to help interns identify their individual internal career success orientations and to articulate how they have experienced their careers thus far.

\section{Interviews}

Semi-structured interviews that followed an ethnographic interview protocol, in that they were informal and conversational (Spradley, 1979), were then used as a follow-up from the card sorting process. The slight modification was that some of the questions were organised according to themes. These allowed interns to reflect on their choice of significant career success orientations and to explore their internship experiences in relation to these career success orientations. Interview guides were created for this purpose. Care was taken to ensure that the interviewer did not necessarily interrupt, yet took advantage of opportunities to ask additional or clarifying questions and keep the interview on track (Gillham, 2005). Interviews were taped, transcribed and analysed.

The following questions were posed to the interns following their card sorting:

1. Why is (top card) career success orientation the most significant choice for you?

2. How have you been able to express yourself in the organisation in line with your career success orientation choice?

3. What do you believe are the advantages and disadvantages of your most significant career success orientation choice?

4. What were your career expectations going into the graduate programme, were your expectations met, did they change or have they remained the same over time? Please explain.

5 . What has been your experience on the company graduate programme?

6. To what extend has the graduate programme enhanced your career success?

7. What support did the organisation provide to you in line with your own career success expectations?

8. How does the organisation need to manage you in order to get the best out of you, given your career success choice?

9. How do you believe the organisation should recognise and reward you?

10. Do you have any suggestions on how the programme can be modified or improved to better suite your career needs?

11.In your view, what can the organisation do to retain its graduates?

12. Which career success orientation do you believe the organisation values the most and why?

Analysis

Any human experience can be analysed. Spradley (1979) identified four kinds of ethnographic analysis. These are: domain analysis ["a search for the large units of cultural knowledge" (p. 94)]; taxanomic analysis ["a search for the internal structure of domains and leads to identifying contrast sets" (p. 94)]; componential analysis ["a search for the attributes that signal differences" (p. 94)] and theme analysis ["a search for ... relationships... and how they are linked... as a whole" (p. 94)]. For the purpose of this study, internship experiences (domains) were analysed in relation to internal career success orientations (taxonomy). These may be referred to as the search for parts of the experience specific to internship programmes as conceptualised by the interns. The interviews were semi-structured to provide for a componential analysis. Specific themes were analysed 
in relation to the domain and taxonomy. These themes included: intern expectations getting into the programme, intern experiences on the programme (both positive and negative), how interns preferred to be managed, support interns required from the organisation, what the organisation can do to improve the programme and retain interns, and rewarding and recognising interns.

\section{Quality considerations}

For the purposes of objectivity and trustworthiness, the principles suggested by Heyl (2001) were adhered to. These were: listening well and respectfully, developing an ethical engagement with the participants at all stages of the project; acquiring self-awareness of the interviewer's role in the construction and meaning during the interview process; being cognisant of ways in which both the ongoing relationship and the broader social context affect participants, the interview process, the project outcomes, as well as recognising that dialogue is discovery and only partial knowledge will ever be attained.

Although it was difficult to achieve complete objectivity in the interviews, interns were allowed to speak and ask clarifying questions. The interviewer listened actively in order to do justice to the objective of this study. The interviewer took notes on the interview guides. The interviews were taped and transcribed to ensure reliable and valid analysis.

\section{Research procedure}

An introductory electronic mail, introducing the research, was forwarded to all interns that have been employed through an internship programme since 2000. The HR Director formally requested participation and indicated the value of the research to the individuals and the organisation. The process was outlined and confidentiality was highlighted. Permission to tape the sessions was requested. None of the interns objected to being interviewed or to the sessions being taped. An interview schedule was drawn up and one-hour interviews were allocated per intern.

At the beginning of the session, five cards with the essence of each career success orientation were issued to interns. They were asked to sort five career success orientation cards from the most significant to the least significant, placing the most significant on top. The interviewer verified the card sorting order. Interviews were conducted, based on a guide, following from the career success orientation cards sorting order and focusing only on the most significant career success orientation choice for each intern.

At the end of the interviews, the interns were asked to sort the cards again, focusing this time on their perceptions of the career success orientation that the organisation values the most. The interviewer also verified this card sorting order.

\section{FINDINGS}

\section{Card Sorting}

Data collected from the interviews and card sorting process were analysed. The career success orientation card sorting process results are represented (see Figure 1 and Table 2). The results indicated that the majority of interns interviewed predominantly identified themselves as "getting high" (nine out of eighteen interns), followed by "getting balanced" (five out of eighteen), then "getting ahead" (three out of eighteen) and lastly one intern identified herself as "getting free". None of the interns identified with a getting secure career success orientation.

When the interns re-ordered the cards in line with what they perceived the organisation to value, they reflected both getting high (seven out of eighteen) and getting balanced (seven out of eighteen) as the orientation mostly valued by the organisation and therefore, reflecting its culture. This was followed by both getting free (two out of eighteen) and getting secure (two out of eighteen) and no one selected getting ahead career orientation as being valued by the organisation.

More specifically, seven of the nine interns who selected getting high also perceived the organisation to value the same getting high orientation. The other two interns perceived the organisation as valuing a getting free and a getting secure career orientation. Three of the five interns who selected getting balanced also perceived the organisation as valuing the same getting balanced orientation. The remaining two interns perceived the organisation as valuing a getting high career orientation. It seemed therefore that there was an adequate fit between the interns own career success orientation and that of the organisation. (See Figure 1).

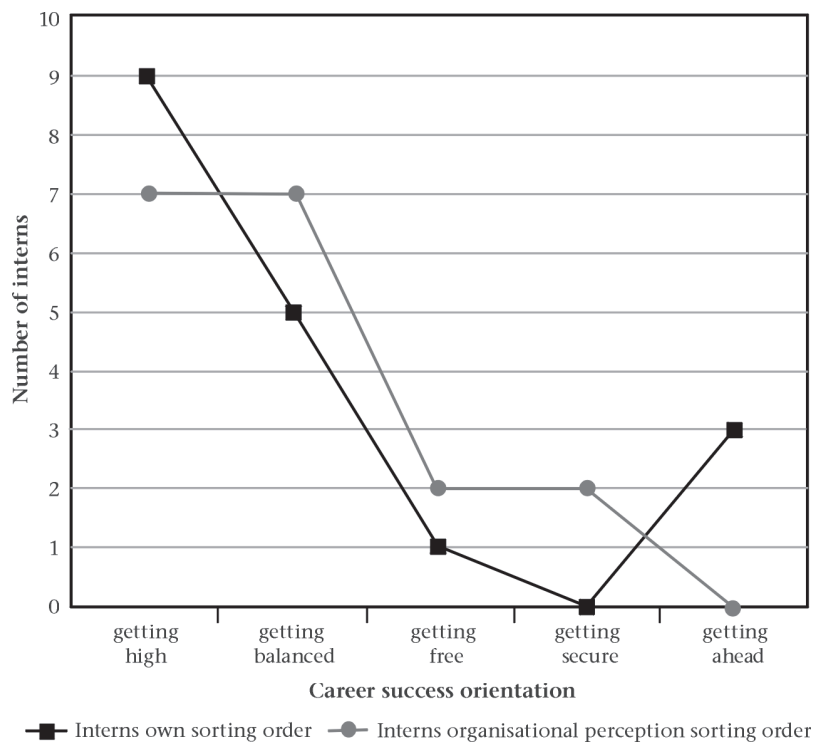

Figure 1: Graphical representation of career success orientations card sorting results

\section{Intern Interviews}

Intern expectations

What follows is a summary of expectations that interns expressed prior to joining the programme. This represents a combination of their own expectations and their perceptions of what the organisational representatives "sold" to them during the selection phase into the programme.

Interns had limited expectations going into the programme. However, the positive energy and interactions with the intern programme coordinators and staff members experienced during the selection phase left them with a general sense that the organisation is caring. Interns' expectations included the need to get to know the organisation better, to create relationships that will be useful in shaping their careers and fast track their career development. They viewed the internship programme coordinators and managers as warm and friendly during the selection phase and were impressed by the interesting and creative environment.

"I guess the culture played a part in it...the people looked like they were very happy and confident. There was a certain aura about them that made me feel that these were the kind of people I would like to work with" (intern 6).

"The environment looked vibey, the people were very relaxed, I still remember this one manager sharing his Snacker bar with me during the interview" (Intern 10). "My expectations were purely to get exposure to the organisation as a whole, to get a good understanding of who did what, and to build up a network of people that basically were in different areas" 
TABLE 2

CAREER ORIENTATION CARD SORTING RESULTS

\begin{tabular}{|c|c|c|c|c|c|c|}
\hline \multicolumn{2}{|c|}{ Intern card sorting order } & \multirow{2}{*}{$\begin{array}{c}\text { Getting high } \\
3\end{array}$} & \multirow{2}{*}{ 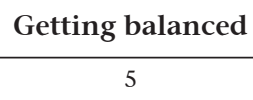 } & \multirow{2}{*}{$\frac{\text { Getting free }}{2}$} & \multirow{2}{*}{$\begin{array}{c}\text { Getting secure } \\
4\end{array}$} & \multirow{2}{*}{$\begin{array}{c}\text { Getting ahead } \\
1\end{array}$} \\
\hline 1 & own sort & & & & & \\
\hline & org perception sort & 4 & 2 & 1 & 5 & 3 \\
\hline \multirow[t]{2}{*}{2} & own sort & 1 & 2 & 3 & 5 & 4 \\
\hline & org perception sort & 1 & 3 & 5 & 2 & 4 \\
\hline \multirow[t]{2}{*}{3} & own sort & 2 & 1 & 5 & 3 & 4 \\
\hline & org perception sort & 1 & 3 & 2 & 4 & 5 \\
\hline \multirow[t]{2}{*}{4} & own sort & 3 & 2 & 5 & 4 & 1 \\
\hline & org perception sort & 3 & 1 & 5 & 4 & 2 \\
\hline \multirow[t]{2}{*}{5} & own sort & 1 & 4 & 3 & 5 & 2 \\
\hline & org perception sort & 4 & 3 & 2 & 1 & 5 \\
\hline \multirow[t]{2}{*}{6} & own sort & 2 & 3 & 1 & 4 & 5 \\
\hline & org perception sort & 2 & 1 & 3 & 4 & 5 \\
\hline \multirow[t]{2}{*}{7} & own sort & 1 & 2 & 3 & 4 & 5 \\
\hline & org perception sort & 1 & 3 & 2 & 4 & 5 \\
\hline \multirow[t]{2}{*}{8} & own sort & 1 & 2 & 4 & 5 & 3 \\
\hline & org perception sort & 2 & 1 & 3 & 4 & 5 \\
\hline \multirow[t]{2}{*}{9} & own sort & 1 & 3 & 4 & 5 & 2 \\
\hline & org perception sort & 3 & 2 & 5 & 1 & 4 \\
\hline \multirow[t]{2}{*}{10} & own sort & 1 & 5 & 4 & 2 & 3 \\
\hline & org perception sort & 1 & 2 & 3 & 4 & 5 \\
\hline \multirow[t]{2}{*}{11} & own sort & 1 & 4 & 2 & 5 & 3 \\
\hline & org perception sort & 2 & 3 & 1 & 5 & 4 \\
\hline \multirow[t]{2}{*}{12} & own sort & 1 & 2 & 3 & 4 & 5 \\
\hline & org perception sort & 2 & 1 & 3 & 4 & 5 \\
\hline \multirow[t]{2}{*}{13} & own sort & 2 & 1 & 3 & 5 & 4 \\
\hline & org perception sort & 2 & 1 & 3 & 4 & 5 \\
\hline \multirow[t]{2}{*}{14} & own sort & 1 & 2 & 3 & 4 & 5 \\
\hline & org perception sort & 5 & 1 & 3 & 4 & 2 \\
\hline \multirow[t]{2}{*}{15} & own sort & 3 & 1 & 5 & 4 & 2 \\
\hline & org perception sort & 2 & 1 & 5 & 4 & 3 \\
\hline \multirow[t]{2}{*}{16} & own sort & 3 & 2 & 5 & 4 & 1 \\
\hline & org perception sort & 1 & 2 & 4 & 3 & 5 \\
\hline \multirow[t]{2}{*}{17} & own sort & 3 & 1 & 2 & 4 & 5 \\
\hline & org perception sort & 1 & 4 & 3 & 5 & 2 \\
\hline \multirow[t]{10}{*}{18} & own sort & 2 & 1 & 4 & 3 & 5 \\
\hline & org perception sort & 1 & 3 & 2 & 4 & 5 \\
\hline & ACTUAL NUMBERS & & & & & \\
\hline & & Getting high & Getting balanced & Getting free & Getting secure & Getting ahead \\
\hline & Interns own sorting order & 9 & 5 & 1 & 0 & 3 \\
\hline & Interns organisational perception sorting order & 7 & 7 & 2 & 2 & 0 \\
\hline & PERCENTAGES & & & & & \\
\hline & & Getting high & Getting balanced & Getting free & Getting secure & Getting ahead \\
\hline & Interns own sorting order & $50 \%$ & $28 \%$ & $5 \%$ & $0 \%$ & $17 \%$ \\
\hline & Interns organisational perception sorting order & $39 \%$ & $39 \%$ & $11 \%$ & $11 \%$ & $0 \%$ \\
\hline
\end{tabular}

(Intern 2). "My expectation was that it was a door into the business world. It was an opportunity for me to learn and get experience" (Intern 16). "Firstly, I had no expectations. The graduate programme promoted fast tracking us into management roles, not that it was specifically meant for me, but it was the offer communicated to us" (Intern 6). "It seemed to be quite an exciting place to be. They might not be doing it very well but they are trying, and they are willing to try these things that I had actually been reading about" (Intern 12).

For the next section, the focus is on the specific interview components in relation to the different career success orientations (the taxonomy) with the exception of the getting secure career orientation as none of the interns selected it as significant. Each interview component of each career success orientation will reflect the general view of the participants with representative quotes.

\section{Getting High Career Orientation}

This was the most dominant career success orientation selected by the interns.

\section{Positive intern experiences}

The getting high career orientation appreciated the opportunity to explore interesting, varied and challenging projects. They were pleased by the social and relational nature of the organisation as they were able to build useful relationships. These interns 
also valued the way in which the programme was structured to provide for involvement and learning opportunities.

"I think it is all about the challenge; the organisation has provided incredible opportunities over the years. I am hugely grateful, but it has been a great challenge and an awesome opportunity. To me it is about enjoying what you do and that comes with the challenge" (Intern 11). "I made good friends and created networks that can be beneficial in future" (Intern 7). "Good exposure, people get to know who you are and remember you when interesting projects come up" (Intern 12), and "I absolutely loved the programme, I am a social creature, I loved going away on the breakaway weekends" (Intern 2). "I think the programme was structured very cleverly; they don't expect output but they expect you to learn via ad hoc stuff - you need to be busy and you need to be learning" (Intern 8).

\section{Negative intern experiences}

Fast tracking did not appeal to the Getting High interns. They expressed a need for structure, guidelines and feedback on how they were performing in their roles even though this need may not be necessarily associated with this orientation. They did not enjoy being inundated with administrative work during their internship year and preferred work that was challenging and not repetitive. These interns believed that relationships were more valued than performance, and were concerned that a heavy focus on relationship building could potentially have negative consequences for the organisation. Interns expressed a loss of their privileged status within the organisation when programme facilitators ended their formal involvement with interns.

"They look into fast tracking people into managers, I'm not really trying to do that" (Intern 14). "The organisation is so informal and the lack of structure sometimes brings a feeling of being way above my head" (Intern 12). "Sometimes there is lack of structure. It can be frustrating at times. To be honest I have never had set goals or set appraisals" (Intern 8). "It does get frustrating when you are bogged down with admin." (Intern 7). "If you are coming from varsity and you were learning everything and come here and do the same thing everyday - personally I would get bored" (Intern 14). "The nurturing by the HR team disappeared after placement into a permanent position; it almost became line manager's responsibility" (Intern 12). "I haven't seen evidence that hard work really gets you places, it is more how you relate to people" (Intern 14).

How interns preferred to be managed

The getting high interns liked the freedom to be innovative and creative and to be provided with variety and novelty.

"What I like is the idea of being innovative and coming up with ideas" (Intern 7). "I like things that are different, I don't like doing the same things over and over, I'm looking for something interesting and new to pick up" (Intern 12).

Support interns required from the organisation

The getting high interns valued the support from HR, line managers and mentors. They appreciated their privileged position. They also believed that the organisation's managers and mentors were providing adequate support. They nevertheless realised the importance to be self-motivated.

"Grads are privileged compared to other people. I had a good relationship with HR from the day I started; I felt that when I had a problem she would listen more because I came through the grad programme" (Intern 14). "The organisation is doing enough but is also not going to hand everything to you on a platter, you have to take the initiative and opportunities, you have got to see the gaps and fight for what you want" (intern 10). "I think it's a balance between management and mentorship" (Intern 8).
What the organisation can do to improve the programme and retain interns

These interns expressed a need for management to be more involved with induction and orientation when introduced to a specific function, with a particular focus on functional clarity and opportunities.

"They should have a workshop for each division [run] by the top dogs in those divisions - [they] should sit down and have a small workshop for the new graduates coming in and explain who they are and what they do" (Intern 2). "We definitely have to put structures in place so that they know what is out there, or that they have the opportunity to get out of what they are doing" (Intern 11).

Rewarding and recognising interns

These interns were of the opinion that the organisation offered good intern salaries, which served as additional motivation for them to join. They also enjoyed the recognition given by the organisation. A single view was that his/her salary was not market related.

"The salary offered was more than any other internship offers received so far" (Intern 8). "Well, in my first year I won the group Oscar. That was great, it was awesome" (Intern 2).

"I have received recognition from my line manager to wider director levels - people know what you are doing" (Intern 10). "I felt the organisation has looked after me ... financially, there are good bonus structures and I have been given a great company account to work on" (Intern 11). "I know I am not being paid in line with the market" (Intern 14).

\section{Getting Balanced Career Orientation}

This was the second most dominant career success orientation selected by the interns.

\section{Positive intern experiences}

The getting balanced interns understood that even though work was important, it needed to be balanced with other aspects of life that were equally important. They appreciated meaningful work and the relaxed culture.

People must enjoy the team and do their work well" (Intern 3). I think it is important that you spend a lot of time at work and that you enjoy what you do at work (Intern 3). "I am enjoying what I am doing, and I am still learning a lot which to me is quite important. I certainly enjoy the culture of the company and I enjoy the fact that it doesn't matter if you are young or old, if you perform well enough you get somewhere quite quickly and [get] recognised" (Intern 3).

Negative intern experiences

These interns expressed concern about the pressures to deliver results even though the culture was relaxed and fun oriented.

"There is a lot of pressure for results and profitability in our team. I think if you are too serious about what you are doing you could have a nervous breakdown. I have seen people get very stressed by the time they were 40" (Intern 3).

"They were forever going on about the fun culture and access to the people and everyone willing to help... I felt the pressures to deliver were masked" (Intern 17).

How interns preferred to be managed

Constant feedback and recognition for a job well done were important to some of the getting balanced career orientation interns.

"For me, recognition for a job well done...I also think constant feedback is always good" (Intern 3) 
Support interns required from the organisation

These interns required feedback on their performance and training opportunities as part of support from the organisation.

"I think the support that I got from my manager and mentor has been excellent - six months' appraisals, objectives, development planning, hard learning and soft skills. I need to develop to be a better leader" (Intern 3).

What the organisation can do to improve the programme and retain interns

The getting balanced interns mentioned the need for clear job roles. The clarification, matching and management of expectations from both interns and managers were viewed as important.

"The most important thing is that if an area is going to bring in an intern, there needs to be a position for him or her. The reason a lot of guys left is that they were sort of pushed around bored, with not enough to do" (Intern 3). "I think it is managing expectations. Some grads come in with big expectations and no one manages that...I think remuneration is also important in terms of retaining grads, maybe they need to be educated as to what market related salaries are and what their worth is in terms of their jobs, and again, more feedback" (Intern 3). "The whole fast tracking thing has a huge appeal for grads, but it should just be framed with proper expectations behind it...it can become a reality but it should be well structured" (Intern 17).

\section{Rewarding and recognising interns}

Being rewarded for work well done and recognised as adding value to the team was important for the getting balanced interns.

"So far recognition has been great, I haven't really adjusted to seeing myself as the star they seem to think I am, it has been good and what is nice is that to some extent, I feel I have a lot of flexibility as to what I want to do as a result" (Intern 17).

\section{Getting Ahead Career Orientation}

This was the third most dominant career success orientation selected by interns.

\section{Positive intern experiences}

Feedback from the getting ahead interns indicated that opportunities for success were not necessarily company wide but division specific and that they would look for advancement opportunities within these divisions.

"I want to grow as fast as possible. The advantage is that it keeps me on my toes and I want to strive to do better, to gain more so that I can get into those positions" (Intern 16). "It was an enabling environment for me...it has worked well in my favour personally, in terms of performance... for me it goes a long way. I have already looked at divisions where I think my career should be going and have already spoken to people and trying to work with them to see if I will fit in" (Intern 4).

Negative intern experiences

These interns expressed the need for continuous development after the formal programme and to be introduced to fellow interns joining the organisation.

"The biggest challenge for me is not actually the intern programme, it is the year or two after the programme - the organisation does nothing about that" (Intern 1). "I wouldn't be able to tell you who the grads are, there was no formal introduction. I know some of them because they are my friends or I have met them through other people but no formal meeting" (Intern 16).

How interns preferred to be managed

The getting ahead interns preferred autonomy and not being micro managed. However, they realise that in order to get ahead, they would have to relay on competent managers.
"I think what works for [me] is to be loosely managed. If I am closely managed I do not perform well and I always get nervous" (Intern 4). "Taking your career past the intern programme is very dependent on your manager...If your manager is good and well trained you will do well and you will fly" (Intern 1).

Support interns required from the organisation

They had an expectation for the programme to materialise into a clear and structured career path in line with their specific strengths and weaknesses.

"There is one area I do need to know, the career path now. I have had a great two years, I have done well, I have moved about, but now it is the career path, I need someone to sit down with me and say 'choose your direction now', these are a couple of options" (Intern 1). "... a bit of career planning in terms of where you are now, this is your potential and these are your weaknesses" (Intern 16).

What the organisation can do to improve the programme and retain interns

The getting ahead interns wanted the programme to be streamlined in the following ways: specific positions and job roles allocated to interns, selection of mentors that they can relate to and more structure initially with the possibility of international exposure on completion of the programme.

"Only employ the number of people as to the number of roles you have...I would have [a] more structured programme for the first year in terms of growth and knowledge" (Intern 16). "I want to be part of the international team, I think that's where my skills are, I have been able to adapt to the culture well and I understand the business" (Intern 16). "There needs to be a better selection of people. I think if you want a mentor you have to find someone who is not too senior in the organisation but one who has been around for a while and knows the ropes" (Intern 16).

Rewarding and recognising interns

The getting ahead interns were satisfied with the way they were being rewarded and recognised during the programme. However, they expected rewards and recognition not to be limited to the internship year.

"I have been recognised well. I think my pay is fair for what I have done. I have also received one of our values awards at our conference, which was quite a big prize. That recognition was quite a big prize. That recognition, and being noticed, is great in terms of getting ahead. But having said that, I don't want it to sort of stagnate, I want to keep increasing my salary and I want to keep getting nice bonuses" (Intern 1).

\section{Getting Free Career Orientation}

This orientation was represented by a single intern.

Positive intern experiences

This intern enjoyed being valued in his/her division.

"In my division they place a lot of emphasis on you. I would say I have been successful but I am just thinking it is also divisionspecific (Intern 6). "I feel I am in the best place...I wont consider going into another division" (Intern 6).

Negative intern experiences

This intern was of the opinion that the internship is structured around the needs of the organisation and not so much around the needs of the interns. Interns were under-utilised and the programme was not structured properly. The need for meaningful and challenging work was expressed.

"Once placed, it was almost their decision as to what they do with you. The problem with that if you studied something that you have an interest in and you still want to do... you are not getting the right exposure" (Intern 6) 
How interns preferred to be managed

This getting free intern expressed a need for an appreciative approach by management for his/her performance.

"They must value me on my performance - they must measure my performance on what I have delivered" (Intern 6).

Support required from the organisation

This intern valued the support she received in terms of formal training during the internship year.

"My mentor suggested that I go through a course which has really helped me. They have really helped build me up in terms of training" (Intern 6).

What the organisation can do to improve the programme and retain interns

This intern was of the opinion that the formal internship contract should incorporate specific performance measures and be monitored accordingly under the supervision of a dedicated mentor or line manager.

"I think before they place someone in a division, get a mentor or line manager to allocate someone who can dedicate their time to train them" (Intern 6). "Structure the programme properly and make sure interns know how to perform - have a written contract between the organisation and the intern - I think everything should just be checked on and measured" (Intern 6).

\section{Rewarding and recognising interns}

This intern wanted to be recognised not in public but rather by the people that she works closely with.

"Public recognition is not really my focus; if I get a job well done with the people I am working with - it would be nice to have recognition from those people around me, not really for the whole company to know" (Intern 6).

\section{Interns' Perceptions of Organisational Career Success Orientation}

The interns regarded Getting High and Getting Balanced as the two career success orientations that they perceived the organisation to value the most. Below is a summary of specific interview components reflecting the two orientations perceived as most valued.

\section{Getting High}

Some of the interns felt that the organisation lived up to the getting high image while others cautioned that the organisational actions may not always live up to the getting high talk.

"Recently with the programmes they have put in place, they definitely try and create excitement and adventure" (Intern 16). "...the sort of talk - emphasis on culture, being different, being innovative. That is the sort of message you get from senior management" (Intern 3). "What is new and challenging for an innovative company - how can you do things differently" (Intern 17). I think this is also to their detriment, it is just that the Getting High philosophy to me has always focused on ideas and not implementation"

Getting Balanced

Some of the interns were convinced that the organisation made a real effort towards establishing a getting balanced approach to work. However, others were worried that this emphasis may be to the detriment of the organisation's financial well-being.

"They promote the 'work hard play hard' [ethic], you must work hard but always make time for other things other than work" (Intern 6). "They have got a gym here and we do a lot of fun stuff apart from work" (Intern 1). "You just have to look at the hours; everyone here is in at $8 \mathrm{HOO}$ and we leave at 16H3O, sometimes it seems so relaxed and you wonder how the organisation makes money and stays competitive" (Intern 14).

Interns viewed the organisation as also valuing a combination of getting free and getting secure but to a lesser extent. None of the interns perceived the organisation to value a getting ahead career success orientation. (See Figure 1).

\section{DISCUSSION}

\section{Interpretation and Recommendations}

Actionable data, in line with the different career success orientations were provided by the participants that would make constructive changes to the internship programme possible. The dominant career success orientations of the interns were getting high and getting balanced. These career success orientations matched the perceived organisational career culture. Given this context, the internship programme may be regarded as adequate. However, needs for improvements were expressed. These improvements to the internship programme may be achieved with relative ease by the organisation. Given that this study was exploratory, caution should be exercised not to generalise these findings. An internship programme should therefore not be reduced to accommodate only these two orientations but rather to provide for all career success orientations. This will ensure that no intern will feel alienated on the programme and will provide the necessary psychological career success for each and every intern. This may provide interns with the values and career identity necessary to deal effectively with the demands of careers that have become more protean and boundaryless in nature (Inkson, 2006; Briscoe, Hall \& De Muth, 2006).

Some of the opinions expressed by interns - their theories in use (Argyris, 1990) i.e. their specific contextualised needs, views and expectations - were not always consistent with their espoused theories (Argyris, 1990) i.e. the dominant career success orientation choice as per the card sorting techniques. These contradictions may be explained by Derr's (1980) view that during the early career stage, career orientations are still in the process of being established. He highlighted that young adults at early stages of their careers have numerous needs, values, attitudes and abilities that start to coalesce into several patterns or trends. Furthermore, it seems that career decisions are based on a complex structure of career success orientations rather than a dependence on a singular career success orientation. Although the focus of this study was on the dominant orientations, and a group of interns share common dominant career success orientations, they all differ in terms of the complete ranking order of their career success orientations. It may not only be the dominant career success orientation that guide interns' thinking about their career development; for example in stressful times other less dominant orientations may come to the fore.

It is recommended that the organisation introduce a comprehensive career framework based on career success orientation theory. What follows are suggestions in the form of a "blueprint" on how an internship programme could be structured in order to provide personal meaning of career success. These are in line with Derr's (1986) framework for managing different career orientations.

Getting High - Internship programme elements:

Nature of work: Expose interns to interesting and varied work assignments or projects within a job role or function. 
Networking and relationships: Create networking opportunities with staff members who have worked on exciting projects where interns can build useful work relationships.

Mentor selection: Provide a list of mentors that they can access, highlighting the type of work they do and special projects or assignments that they have worked on. Avoid formally allocating only one mentor per intern.

Communication: Provide communication platforms where interns can share their stories about their varied and exciting work or projects.

Recognition: Create an "ideas" reward and recognition structure that encourages development of great ideas that can take the organisation forward. An opportunity to work in another country may be used as a way of creating hype and excitement about projects and work.

Getting Balanced - Internship programme elements: Nature of work: Incorporate non-work related activities as part of the organisational offering and clarify organisational values to allow for self-selection and de-selection based on these values. Minimise business travel and time away from self and family.

Networking and relationships: Provide opportunities to socialise and network within the normal working hours.

Mentor selection: Provide a list of mentors that they can access, indicating the values that these mentors uphold to facilitate easy matching.

Communication: Provide an opportunity to input and shape the roles and projects.

Recognition: Incorporate personal time off in rewards or groupbased rewards "experience with family or with friends" type rewards. An opportunity to work in another country may be attractive provided family can be brought along.

Getting Ahead - internship programme elements:

Nature of work: Provide challenging and competitive work assignments, clear work and performance goals and measures and clarify opportunities for movement within the organisation.

Networking and relationships: Provide an opportunity for interns to interact with senior members of staff.

Mentor selection: Establish mentoring relationships based on seniority so that interns "can access senior people" and high achievers within the organisation.

Communication: Provide a platform for senior staff members to share how they got there and for interns to ask questions.

Recognition: Provide opportunities to self-appraise continually and balance this with organisational feedback on performance. Provide monetary rewards and recognition that further reinforce mobility. An opportunity to work in another country may be a way of rewarding performance.

\section{Getting Free - Internship programme elements:}

Nature of work: Incorporate independent work assignments and focus on the specialist nature of the role. Provide the necessary training and development opportunities focusing on specialist skills.

Networking and relationships: Provide opportunities to network with other staff members who had the opportunity to work on highly specialised projects and assignments in order to share with interns.
Mentor selection: Provide mentoring relationships based on highlevel expertise - i.e. "what interns can learn from this person in the shortest amount of time".

Communication: Provide a platform to share specialist knowledge with others within the organisation and to give specialist talks and presentations to others.

Recognition: Recognise acquisition and application of specialist skills. Opportunities to work in other countries should focus on the need for high-level specialisation or rare skills to be attractive.

Getting Secure - Internship programme elements:

Nature of work: Provide some degree of predictability and outline possible movements and intervals within the organisation.

Networking and relationships: Provide opportunity to network based on organisational identity and values.

Mentor selection: Provide mentors based on familiarity, loyalty, dedication and who have been around and have gained reasonable experience in the organisation.

Communication: Messages to focus on valuing individuals and the consistent contributions they make to the organisation.

Recognition: Recognise consistent contribution to organisational goals and provide attractive organisational benefits.

Past interns may be utilized to the benefit of such a programme by involving them in formal and informal mentoring. This may be done by creating an intern buddy system where past interns can provide new interns with a more realistic view of the work demands and challenges in specific business functions. Past interns may also be involved in the selection and induction of new interns. Technology may also be more effectively utilised to brand and manage the internship programme. For example, this can be achieved by allowing interns a platform to share their experiences and positive stories.

\section{CONCLUSION}

An internship programme on differentiated career success orientations may provide benefits for both the organisation and the individual.

Organisational benefit:

By respecting the diversity of individual career aspirations of interns, it may send the message that the organisation is truly employee centred and is caring. The spin off could be loyalty and commitment to the organisation and the brand, with employees who will contribute effectively towards the achievement of organisational goals as well as acting as positive brand ambassadors for the organisation.

\section{Individual benefit:}

Taking career success orientation into consideration will help interns to establish their career identity soon in their career life cycle, and will help to capitalise on their subjective strengths and interests. This may assist interns to cope better with the demands of a complex world of work.

\section{Limitations of the study}

Participation in the study was voluntary and may have excluded other interns with different views on career success and experiences in the organisation. A further limitation was the researcher's inability to make contact with interns that had already left the organisation - they might have had different experiences to report. Derr's (1986) career success orientation framework was used, and as such could 
have restricted the interns' thinking and views on career success. Furthermore, the group of interns that participated in this research represented only two race groups with a strong male bias.

\section{Recommendations for further studies}

The dominant getting high and getting balanced career success orientations are similar to the needs of the Generation Y employee, a generation born between 1978 and 1998 (Tulgan \& Martin, 2001). These authors reported that this generation expects challenging work, balance, increasing responsibility, to relate to others in person rather than in role, learning opportunities, establishing mentoring relationships, low stress environments, flexibility, fun at work, accessibility, collegiality, respect, constructive feedback and rewards for good performance. This relationship that seems to be obvious may be empirically tested. Another study may try to establish to what extent specific career success orientation is function specific or sector specific. Another study may focus in more depth on the relationship between internship programmes based on differentiated career orientations and successful organisational career branding.

An internship programme, aligned with the differentiation of personalised career success preferences may present a compelling value proposition and a strong employment brand (Van Dyk \& Herholdt, 2004).

\section{REFERENCES}

Argyris, C. (1990). Overcoming organizational defences. Facilitating Organizational Learning. Boston: Allyn and Bacon.

Arthur, M.B., Hall D.T., \& Lawrence, B.S. (1989). Generating new direction in career theory: a case for transdisciplinary approach. In M. Arthur, D. Hall \& B. Lawrence. Handbook of Career Theory. New York: Cambridge.

Bailyn, L. (1989). Understanding individual experience at work: comments on the theory and practice of careers. In M.B. Hall, T.H. Hall, \& B.S. Lawrence. (Eds). Handbook of Career Theory. New York: Cambridge.

Boninelli, I. (2004). Employment branding: Contributing to corporate image and integrated talent management. In I. Boninelli \& T.N.A. Meyer. (Eds). Building Human Capital. South African Perspectives. Randburg: Knowres.

Briscoe, J.P., Hall, D.T. \& DeMuth, R.L. (2006). Protean and boundaryless careers: An empirical exploration. Journal of Vocational Behaviour, 69, 30-47.

Buhlungu, S. \& Metcalfe, A. (2001). Breaking the racial division of labour in knowledge production: Reflection on internship programmes. Perspectives in Education, 19 (2), 67-84.

Carlin, D. (2002). Graduate internship programs in the Humanities: A report from one university. Pedagogy 2 (2) $213-228$.

Carlson, D. S.; Derr, C.B. \& Wadsworth, L. L. (2003). The effects of internal career orientation on multiple dimensions of work-family conflict.

Chompookum, D. \& Derr, C. B. (2004). The effects of internal career orientations on organizational citizenship behaviour in Thailand. Career Development International, 9 (4), 406423.

Coetzee, M. \& Schreuder, A.M.G. (2002). The relationship between career patterns and personality types. SA Journal of Industrial Psychology, 28 (1), 53-59.

De Gouveia, C.M., Van Vuuren, L.J. \& Crafford, A. (2005).
Towards a Typology of gossip in the workplace. SA Journal of Human Resources Management, 3 (2), 56-68.

Denzin, N.K. \& Lincoln, Y.S. (2000). (Eds). Handbook of qualitative research. $\left(2^{\text {nd }}\right.$ ed). Thousand Oakes, CA: Sage.

Derr, C.B. (1980). More about career anchors. Work, family, and the career. New Frontiers in Theory and Research. New York: Praeger.

Derr, C.B. (1986). Managing the new careerists: the diverse career Success orientations of today's workers. San Francisco: JosseyBass.

Derr, C. B. \& Laurent, A. (1989). The internal and external careers: a theoretical and cross-cultural perspective. In M.B. Arthur, D.T. Hall, \& B.S. Lawrence (Eds). Handbook of Career Theory. New York: Cambridge.

Dodge, R.B. \& McKeough, M. (2003) Internship and the Nova Scortia Government experience. Education + Training, 45 (1), 45-55.

Driver, M.J. (1982). Career Concepts - a new approach to career research. In R. Katz (Ed), Career Issues in Human Resource Management. Engelwood Cliffs, NJ: Prentice-Hall.

Gabris, G.T. \& Mitchel, K. (1989, Winter). Exploring the relationship between intern job performance, quality of education experience, and career placement. Public Administration Quarterly, 484-504.

Gillham, B. (2005). Research interviewing: The range of techniques. London: Open University Press.

Greenhaus, J.H., Callanan, G.A. \& Godshalk, V.M. (2000). Career Management. ( $3^{r d}$ ed). Orlando: Drydren Press.

Hall, D.T. (1996). The career is dead - long live the career. San Francisco: Jossey-Bass.

Heyl, B.S. (2001). Ethnographic interviewing. In P. Atkinson, A. Coffey, S. Delamont, J. Lofland \& L. Lofland. (Eds). Handbook of Ethnography. London: Sage.

Jones, E. (2006, Summer). Internships: Previewing a profession. Occupational Outlook Quarterly, 50 (2), 16-18.

Inkson, K. (2006). Protean and boundaryless careers as metaphors. Journal of Vocational Behaviour, 69, 48-63.

Rosslee, G. Crous, F. \& Schepers, J. M. (1999). The internal career of the type A personality. SA Journal of Industrial Psychology. 25 (3), 39-43.

Schein, E.H. (1978). Career Dynamics: matching individual and organizational needs. Massachusetts: Addison-Wesley.

Schein, E.H. (1990). Career Anchors: discovering your real values. (Revised Ed). San Diego California: Pfeiffer \& Company.

Schein, E.H. (1996). Career Achors revisited: implications for career development in the $21^{\text {st }}$ century. Academy of Management Executive, 10 (4), 80-89.

Spradley, J. P. (1979). The ethnographic interview. New York: Holt, Rinehart \& Winston.

Terre Blanche, M \& Kelly, K. (1999). Interpretive methods. In M. Terre Blanche \& K. Durrheim (Eds). Research in practice: Applied methods for the social sciences. Cape Town: University of Cape Town Press.

Tulgan, B. \& Martin, C.A. (2002). Managing Generation Y. Amaherst, Massachusetts: HRD Press.

Van Dyk, L. \& Herholdt, J. (2004). Transforming your Employment Brand. The ABSA Experience. Randburg: Knowres.

Van Vuuren, L.J. \& Fourie, C. (2000). Career Anchors and Career resilience: Supplementary constructs? Journal of Industrial Psychology, 26 (3), 15-20.

Wellin, C. \& Fine, G. A., (2001). Ethnography at work: Career socialisation, settings and problems. In P. Atkinson, A. Coffey, S. Delamont, J. Loffland \& L. Loffland (Eds). Handbook of Ethnography. London: Sage. 
